Supplement of The Cryosphere, 15, 663-676, 2021 https://doi.org/10.5194/tc-15-663-2021-supplement C Author(s) 2021. This work is distributed under the Creative Commons Attribution 4.0 License.

(c) (1)

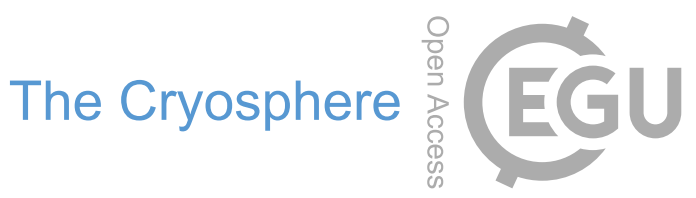

Supplement of

\title{
Recent acceleration of Denman Glacier (1972-2017), East Antarctica, driven by grounding line retreat and changes in ice tongue configuration
}

Bertie W. J. Miles et al.

Correspondence to: Bertie W. J. Miles (a.w.j.miles@durham.ac.uk)

The copyright of individual parts of the supplement might differ from the CC BY 4.0 License. 


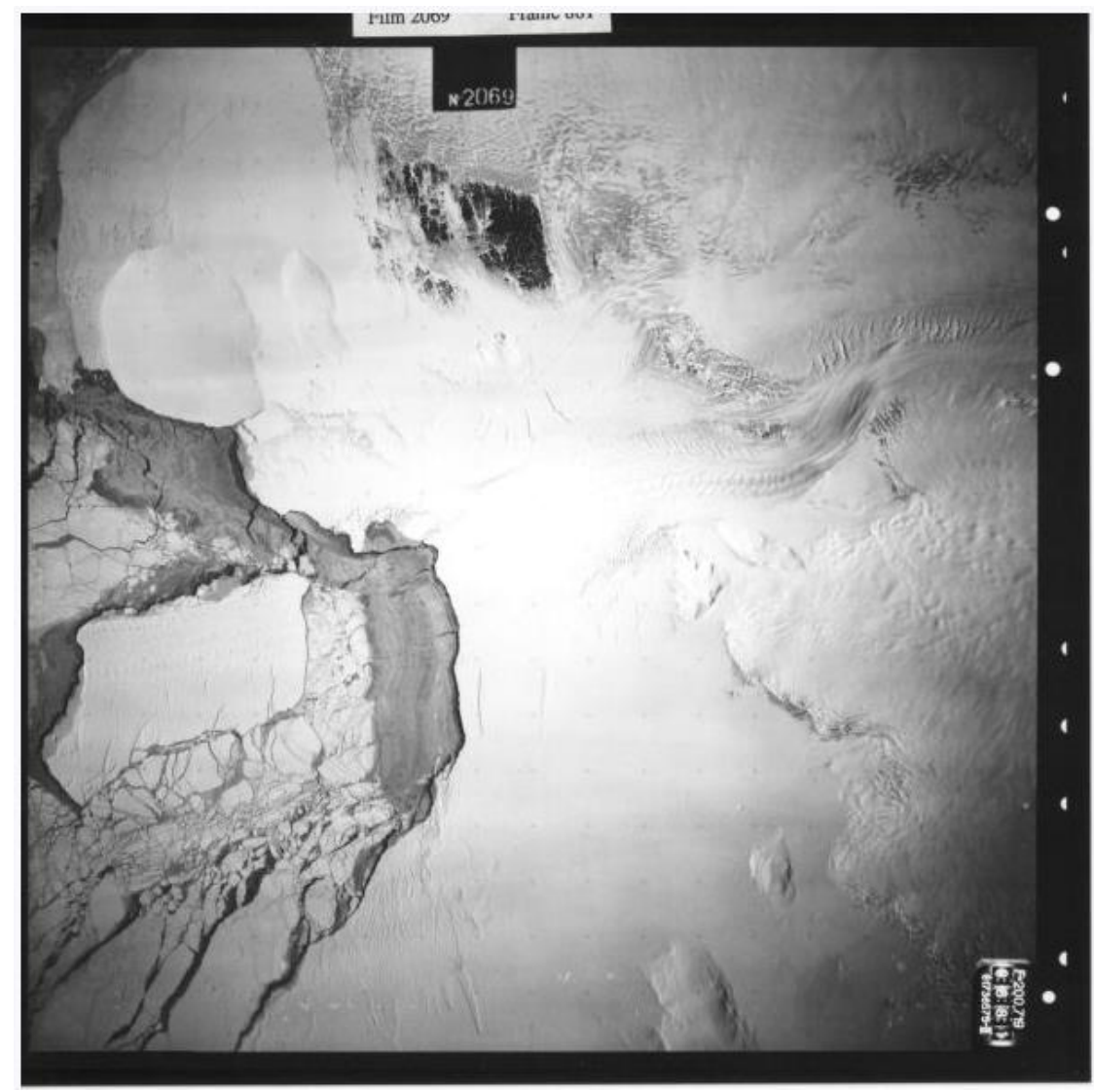

Supplementary figure 1: Resurs - KATE-200 image of Denman Glacier taken on September $23^{\text {rd }}$ 1984 showing Denman's last major calving event. The image preview was obtained from the Australian Antarctic Data Centre - Satellite Image Catalogue, but we could not access the full resolution image. https://data.aad.gov.au/aadc/satellite/display_image.cfm?image_id=354 

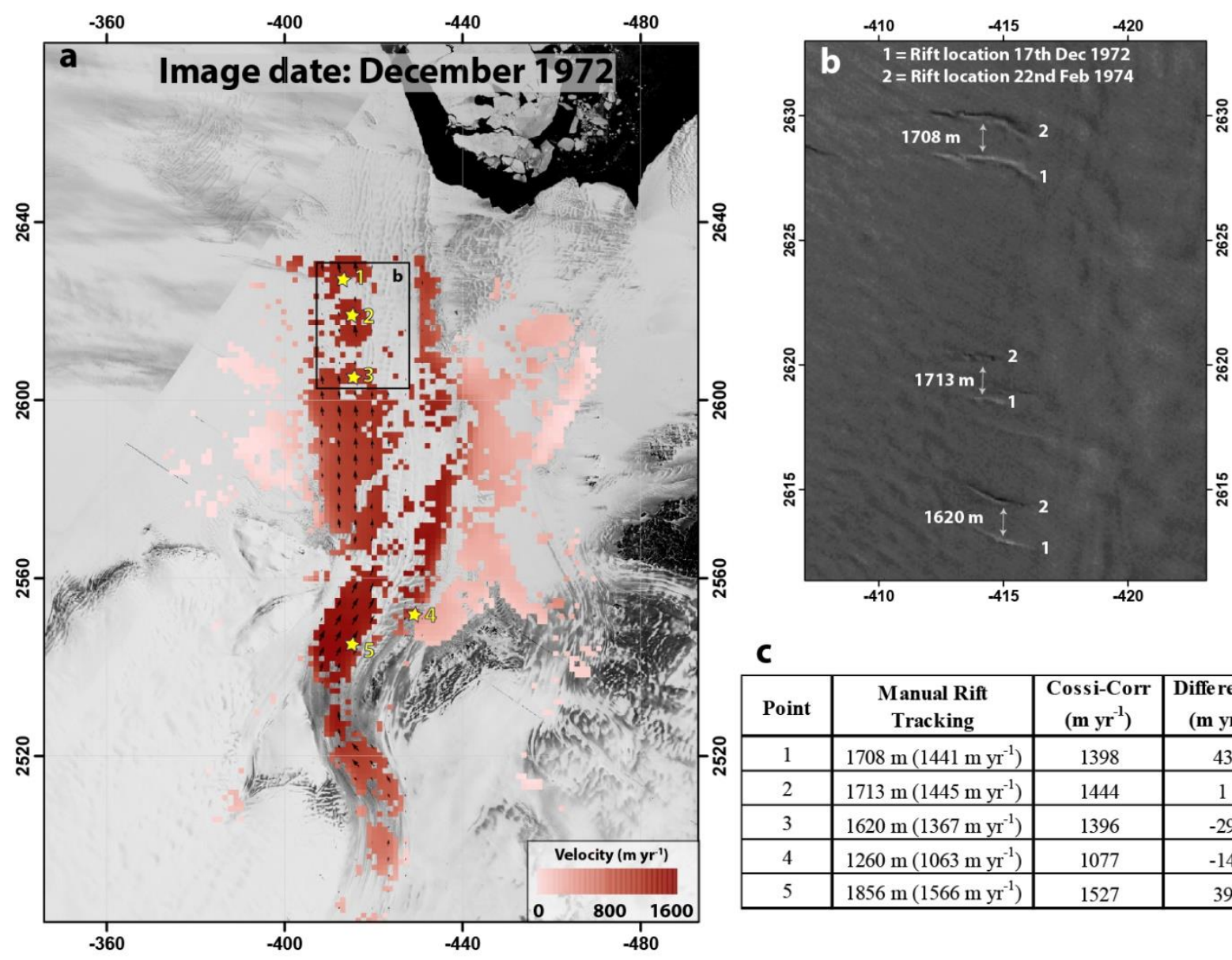

C
\begin{tabular}{|c|c|c|c|}
\hline Point & $\begin{array}{c}\text { Manual Rift } \\
\text { Tracking }\end{array}$ & $\begin{array}{c}\text { Cossi-Corr } \\
\left(\mathbf{m ~ y r}^{-1}\right)\end{array}$ & $\begin{array}{c}\text { Diffe rence } \\
\left(\mathbf{m ~ y r}^{\mathbf{- 1}}\right)\end{array}$ \\
\hline 1 & $1708 \mathrm{~m}\left(1441 \mathrm{~m} \mathrm{yr}^{-1}\right)$ & 1398 & 43 \\
\hline 2 & $1713 \mathrm{~m}\left(1445 \mathrm{~m} \mathrm{yr}^{-1}\right)$ & 1444 & 1 \\
\hline 3 & $1620 \mathrm{~m}^{-1}\left(1367 \mathrm{~m} \mathrm{yr}^{-1}\right)$ & 1396 & -29 \\
\hline 4 & $1260 \mathrm{~m}\left(1063 \mathrm{~m} \mathrm{yr}^{-1}\right)$ & 1077 & -14 \\
\hline 5 & $1856 \mathrm{~m}\left(1566 \mathrm{~m} \mathrm{yr}^{-1}\right)$ & 1527 & 39 \\
\hline
\end{tabular}

Supplementary figure 2: a) 1972-74 velocity values overlain on a Landsat-1 image from 1972. The numbered yellow stars represent the locations where rifts were manually tracked between image pairs. b) Merged composite of the two Landsat-1 images used to compute velocity shown in panel a. This provides a clear comparison of the position of visible rifts in both images, we then manually measure the distance between rift pairs to provide an estimate of displacement in each of the 5 locations shown by the yellow stars in panel a. c) This table shows the difference between the manually estimated displacement of rifts and the corresponding Cossi-Corr computed pixel. The median difference between manual rift tracking and Cossi-Corr pixels is $\pm 29 \mathrm{~m} \mathrm{yr}^{-1}$ or 0.5 pixels (Landsat-1 pixel size is $60 \mathrm{~m})$. 

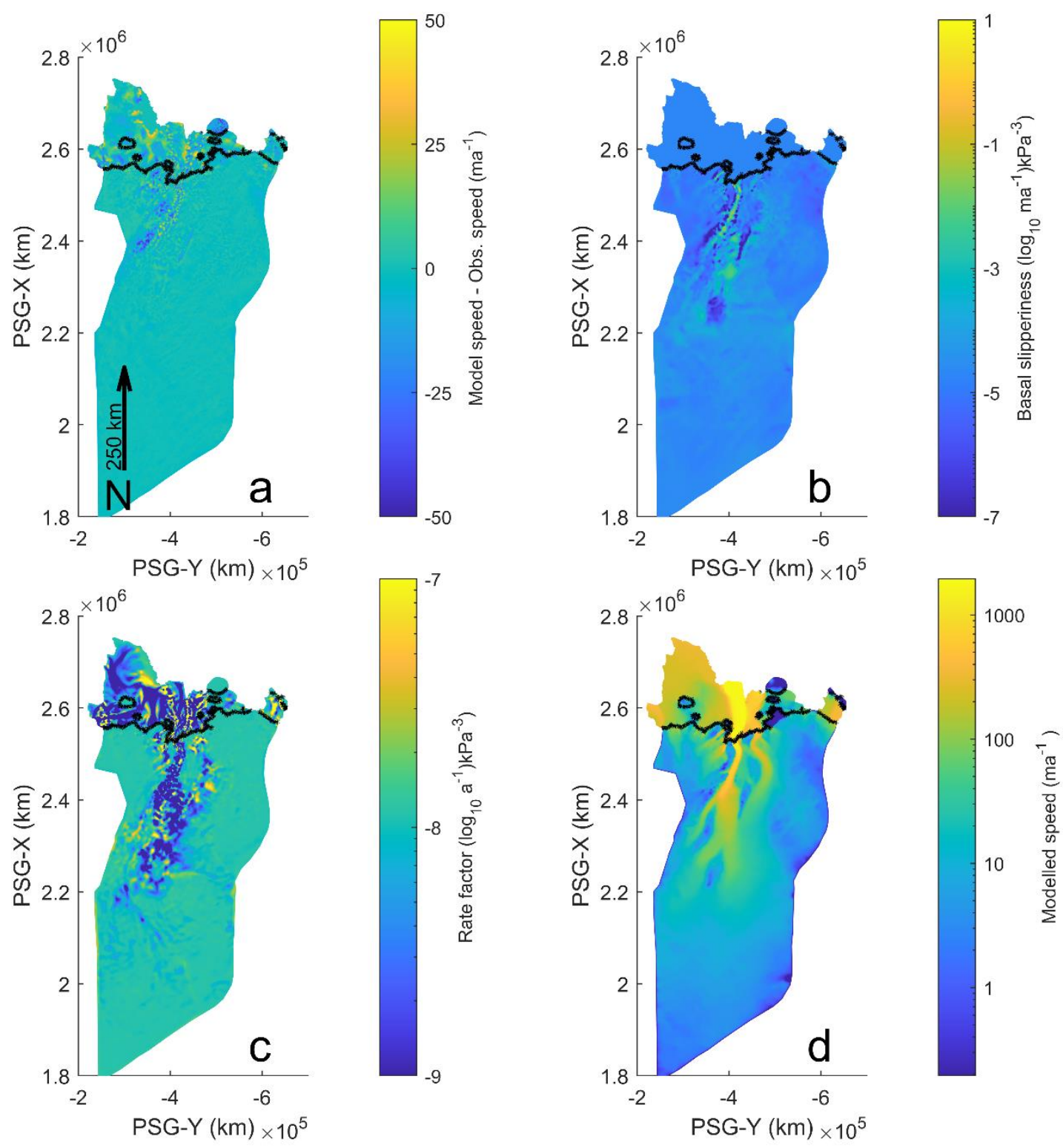

Supplementary figure 3 - Model validation and inverted parameters: a) model speed minus 2009 observations, b) basal slipperiness, $C$, c) rate factor, $A$ and d) modelled speed. The position of the grounding line is shown in black. 


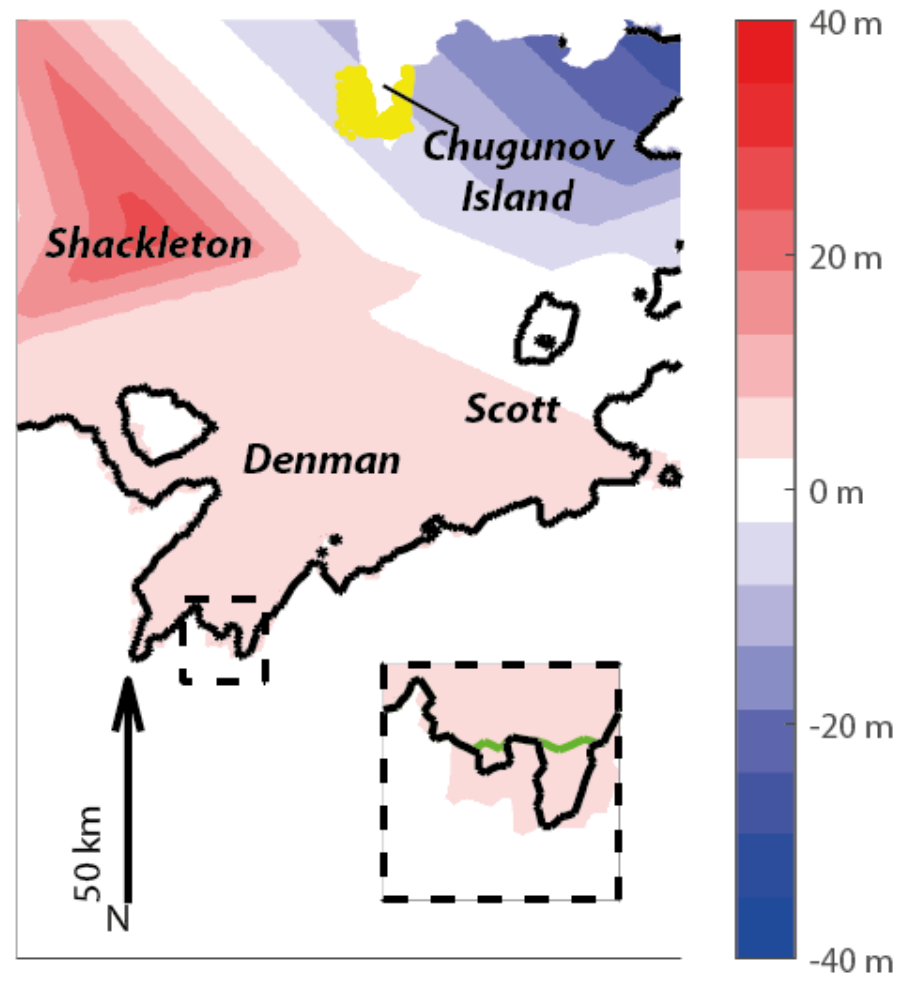

Supplementary figure 4 - Ice geometry perturbation summary: Ice geometry is perturbed in three ways; i) ice shelf thickness change (colours, with red, positive values showing where present day ice thickness has been increased to recreate the 1972 ice geometry), ii) grounding line migration (inset, where the present day grounding line (black) has been advanced $10 \mathrm{~km}$ to a location representing its estimated 1972 position) and iii) grounding of floating ice on the Chugunov island pinning point (yellow area). 